\title{
DEVELOPMENT AND STUDY OF TRIBOLOGICAL PERFORMANCE OF BIO- BASED HYBRID NANOCOMPOSITES FOR BRAKE PAD APPLICATION
}

\section{OLUWAFEMI E. IGE, PROFESSOR FREDDIE L. INAMBAO \& OLUWATOYIN J. GBADEYAN}

Department of Mechanical Engineering, University of KwaZulu-Natal, Durban, South Africa

ABSTRACT
In this study, a novel bio-based hybrid nanocomposite brake pad (BHN) has been developed and investigated to
serve as a functional replacement for metallic, ceramic, and hazardous asbestos-based brake pad materials. Carbon
nanospheres (CNSS) synthesized from agro-waste were incorporated with other carbon-based constituents and additives to
produce brake pads. The tribological, mechanical, and solvent absorption properties of BHN brake pads were examined
with caution and compared with conventional (CON) brake pads. In this work, the properties of friction materials varied
with CNSs loading made with different parameters; the experimental results showed that the brake pad performance
changed with each pad formulation. The BHN brake pad material showed better performance than the CON brake pad in
most tests. The friction coefficient (COF) of the BHNs brake pad samples (0.3 to 0.5) was within the standard of SAE J661
CODE. The BHN brake pad (0.18\% to $1.97 \%$ absorbed lower water content than the CON brake pads (2.02\%), and most
BHN brake pads similarly absorbed a smaller amount of oil (0.11 \% to 0.42 \%) compared to the CON brake pad. Scanning
electron microscopy (SEM) image of CON brake pad worn surface was inconsistent with stress yielding surface texture,
while homogenous dispersion, wear debris, flakes, and plateaus were observed in the BHN brake pad. These improved
properties were attributed to CNSs incorporation and the homogenous dispersion of additives forming a synergistic effect,
producing a tougher structure, which eventually improved BHN brake pad performance.
KEYWORDS: Brake pad, wear, carbon nanospheres, friction composite, scanning electron microscope

Received: Dec 15, 2020; Accepted: Jan 05, 2021; Published: Mar 08, 2021; Paper Id.: IJMPERDAPR20219

\section{INTRODUCTION}

Friction material for automotive braking system application must meet various safety-related guidelines. The expected properties of a brake pad to enable it to perform its function include but are not limited to better tribological properties relating to stopping distance and durability (under regular braking requirements) and fade resistance (at high temperature). Over the years materials that meet this requirement have been designed but challenges remain such as high wear rate, irritating noises, and vibration when these pads are working [1]. Consequently, several experimental designs have been used for commercial brake friction materials to enhance the wear resistance, reduce vibration and eliminate noise when applying brakes [2-7]. The commercial use of a single material never succeeded in meeting the multi-faceted requirements for brake pad application. As a result, multiphase composite materials with up to ten or more components have been used as brake pad friction materials. Materials such as metallic fibers [8-10], organic fibers [11], and ceramic fibers [12] have been used to improve wear resistance and friction stability at high temperature among all the numerous components used at present in commercial brake friction materials. Due to brake pads playing a critical role in vehicle safety, fabricating reliable and secure brake pads has become the focus of friction materials formulation. The polymer-based friction material in automotive braking systems consists of several parts, including friction modifiers, thermosetting binders, reinforcing fibers, and fillers [13]. These additives are incorporated to improve tribological and mechanical 
properties and achieve a suitable brake pad for the braking system. Despite several combinations of material used for brake pad production, the use of carbon-based material continues to be preferred because it provides the required properties for brake pad application. In this regard, the introduction of carbon nanotubes (CNTs) as a filler for brake pad material development has been a huge breakthrough in brake pad production.

Studies have shown that the loading of CNTs increases the nominal contact area, enhances mechanical properties, decreases wear rate, and naturally reduces the friction coefficient [14-16] [17]. The effectiveness of CNTs on improving numerous nanocomposites properties makes it an additive of choice for brake pad manufacturing and also for use as alternative fillers in brake pad friction materials [4, 5, 18-20]. The increase in use of CNTs recently is due to its low-density, high rigidity, and high aspect ratios. Hwang et al. [1] investigated the effect of adding CNTs for brake friction materials production. The material compositions were prepared by replacing the barite with $1.7 \%$ wt. $\%, 4.7 \%$ wt. $\%$, and $8.5 \%$ wt. \% of CNT. The results showed that adding CNTs could improve the thermal friction stability of the materials. Simultaneously, the specific wear rate reduced as the CNT content increased in the formation due to the composite reinforcement by CNT and the high temperature produced by CNTs. Besides, the COF was reduced as the CNT content increased, which could be the undispersed bundles of CNT on the contact surface. Lee et al. [21] examined the tribological properties of brake lining materials containing CNTs. The result also showed that additional CNT content enhanced the composite materials wear and thermal stability. In both situations, the COF decreased as the CNT content increased, which may be due to the lubricity of the CNT content. As stated by Han et al. [22], Jang et al. [23], Cho et al. [3], Deshmukh et al. [24], Kim et al. [25], and Gbadeyan and Kanny [6], braking performance (for example, stopping distance and other related tribological properties) fundamentally depend on a series of solid lubricants contained in the brake pads. Bearing this in mind, one those papers selected carbon-based constituents such as bio-based CNSs, binders, friction modifiers, and reinforcement materials based on the standard composition of the brake pad, inherent properties of the material, and compatibility. Multiwall carbon nanotubes (MWCNTs) and carbon nanotubes (CNTs) have demonstrated numerous advances in the properties of nanocomposites as alternate brake friction materials [4]. This output may be attributed to high toughness and high ratios with low density in CNTs. Although CNTs have many advantages, it is an expensive product and increases the production costs [5].

Similarly, limited studies have reported bio-based filler use for brake friction materials application [26]. In this study, carbon nano-spheres (CNSs) with the same properties as CNTs were synthesized from coil fiber and used as a friction modifier, and the reinforcement offered interlocking connections of other fillers to form carbon and carbon bonds. This structure generally enhances the tribological, thermal and mechanical properties of the composite materials [7, 27, 28]. This work investigates the mechanical and tribological properties of bio-based hybrid nanocomposite materials and evaluates existing brake pad material.

\section{MATERIALS AND METHODS}

\section{Materials}

The binder and hardener were purchased from ATM Composite in Durban, South Africa. CNSs were synthesized by UniZulu, South Africa, while friction modifier and reinforcement materials were purchased from Capital Lab Supplies in Durban, South Africa. The CNSs and friction modifiers were used as a friction additives and fillers. CNSs are a kind of black additive, generally used to enhance the properties of polymeric materials such as thermal conductivity, mechanical and tribological properties [29-32]. Thermal stability additives are often used to regulate brake pad wear and friction, while 
friction modifiers are generally used as internal lubricants $[33,34]$. In this work, reinforcement material was also used to enhance the thermal stability, creep, mechanical strength, and wear resistance of polymer materials [31, 35-37].

Table 1: Bio-Based Hybrid Nanocomposite Composition

\begin{tabular}{|l|c|c|c|c|c|c|}
\hline & \multicolumn{7}{|c|}{ Samples } \\
\hline & BHN 1 & BHN 2 & BHN 3 & BHN 4 & BHN 5 & BHN 6 \\
\hline Materials & \multicolumn{7}{|c|}{ Composite in weight percentage (wt. \%) } \\
\hline Binder & 98.1 & 98.6 & 98 & 98.6 & 97.9 & 98.7 \\
\hline Friction modifier & 1 & 0.3 & 1 & 0.5 & 1 & 0.3 \\
\hline Carbon nanosphere & 0.1 & 0.3 & 0.2 & 0.1 & 0.3 & 0.2 \\
\hline Reinforcement & 0.8 & 0.8 & 0.8 & 0.8 & 0.8 & 0.8 \\
\hline Total & 100 & 100 & 100 & 100 & 100 & 100 \\
\hline
\end{tabular}

To produce bio-based hybrid nanocomposite material, binder was weighed into a beaker and heated up to $70{ }^{\circ} \mathrm{C}$ to reduce the viscosity of the resin and integrate carbon nanospheres and friction modifier. The binder, CNSs, and friction modifier were mixed with a mechanical stirrer at $500 \mathrm{rpm}$ for 60 minutes to achieve uniform distribution. The weight percentage of additives (such as CNSs and friction modifier) was very low in the formulation, as carbon-based additives performance are always important in the polymer matrix. [12]. The biobased hybrid nanocomposite material was cooled down at room temperature and mixed with the catalyst in a ratio of 100 to $30 \%$ by volume $\%$ to ease the process of curing. The reinforcements were added $(0.8 \mathrm{wt}$. \%) to the different compositions, as shown in Table 1 . The mixture was poured into an open mold. Before pouring into the mold, the inner surface of the plastic mold was coated with wax to enable easy removal of the composite material after two days. The composite was de-molded and tested after it had cured for 14 days.

\section{Hardness}

Hardness is the amount of a solid matter resistance to several permanent changes when a compression force or indentation is applied. The hardness of the developed brake pad composite was tested using a Barcol impressor hardness tester produced by the Barber Colman company Illinois, USA. The Barcol impressor hardness tester is good for testing fabricated samples for production control. The hardness samples test was performed following ASTM D 2583 standard test specification [38]. The depth of the indenter point penetration was measured. The hardness test explains the hardness of a material dent point.

The Barcol impressor hardness tester (GYZJ-934-1 model) is widely used to calculate and determine the hardness of composite materials. The impresser has a toughened steel (intender) with an angle of $26^{\circ}$, and a flat point with a diameter of $0.157 \mathrm{~mm}$ and was mounted into a hollow spindle and pressed by a spring-loaded plunger. The indenter point of the Barcol impressor was positioned directly towards the face of the developed nanocomposite sample plate. A downward force was applied constantly by hand until the reading indicator reached a maximum, and the value was recorded. The average of the 15 values taken on developed biobased hybrid nanocomposite plate samples at random was reported.

\section{The Absorption Test}

The absorption rate of brake pads generally affects braking performance [39]. For that reason, the oil and water absorption of the brake pad samples should be investigated. The methods used in this work to determine the absorption of brake pads are outlined below. 


\section{Water Absorption}

The water absorption of the brake pad sample was examined to determine the water absorption rate of the material and the effects of water or humidity exposure. Tests were in compliance with the standard test specification of ASTM D 570-98 [40]. The initial weight of each sample was weighed using a digital electronic balance (Kern Germany model D-72336) with an accuracy of $0.01 \mathrm{~g}$ and recorded as $\left(\mathrm{W}_{0}\right)$ to determine the water absorption rate. The samples were soaked for 24 hours in water at an ambient temperature. After this the samples were brought out from the water, dried with a dry thick towel, re-weighed, and the new weight was recorded as $\left(\mathrm{W}_{1}\right)$. Three samples cut from each brake pad were examined. The average of these three samples was used for graphical presentation and discussion. The water-absorption percentage was determined using equation (1).

$$
\mathrm{P}_{W A}=\frac{W_{1}-W_{0}}{W_{0}} \times 100
$$

Where:

$$
\begin{aligned}
& \mathrm{P}_{W A}=\text { Percentage of water absorption } \\
& W_{0}=\text { Initial weight of water sample } \\
& W_{1}=\text { Final weight of water sample }
\end{aligned}
$$

\section{Oil Absorption}

The oil absorption rate of the developed brake pad sample and its influence on oil was examined using a digital electronic balance (Kern Germany model D-72336) with accuracy of $0.01 \mathrm{~g}$ to weigh the initial weight of each sample and recorded as $\left(\mathrm{W}_{1}\right)$. The samples were soaked in engine oil for 24 hours at an ambient temperature. The rating of automotive engine oil used was SAE40. After this the sample was taken from the engine oil, dried with a thick dry towel, re-weighed, and the new weight was recorded as $\left(\mathrm{W}_{2}\right)$. Three samples taken from each brake pad developed were used and absorption percentages were recorded. The average of nine samples recorded was used for graphical representations and discussion. The oil absorption percentage was determined using equation (2).

$$
\mathrm{P}_{O A}=\frac{W O_{1}-W O_{0}}{W_{O 0}} \times 100
$$

Where:

$$
\begin{aligned}
& \mathrm{P}_{O A}=\text { Percentage of oil absorption } \\
& W O_{0}=\text { Oil sample initial weight } \\
& W O_{1}=\text { Oil sample final weight }
\end{aligned}
$$

Therefore, as per Edokpia et al. [41], the change between the initial and the final weight of each sample was used to calculate the absorption rate.

\section{Wear Rate}

The wear (abrasion) rate refers to the gradual loss of material because of relative motion on the contact surface. An inhouse built pin-on-disc tribometer was employed to examine the non-lubricated sliding wear behavior of the bio-based 
hybrid nanocomposite samples by varying the Vol.\% of carbon nanospheres (0.1 Vol.\%, $0.3 \mathrm{Vol} . \%, 0.3 \mathrm{Vol} . \%, 0.3,0.1$ Vol.\% and 0.2 Vol.\%) in accordance with ASTM G-99. The tribometer was designed precisely for wear measurements and friction. The COF was calculated according to the data of frictional force. A digital electronic balance (Kern Germany model D-72336) with accuracy of $0.01 \mathrm{~g}$ was used to measure the BHN brake pad samples. The wear test was performed on a $230 \mathrm{~mm}$ diameter wear track at different sliding distance from $433.6 \mathrm{~m} / \mathrm{s}$ to $2168.0 \mathrm{~m} / \mathrm{s}$ with a fixed load of $30 \mathrm{~N}$ and $0.7 \mathrm{~m} / \mathrm{s}$ sliding speed. The sample wear loss is calculated as the difference between the initial and final weight of the sample. The average of the six samples were recorded. The samples' worn surfaces were investigated using a scanning electron microscope (SEM) to check the wear tracks after the friction test. Based on the wear properties studied, the potential of the wear mechanisms was addressed.

\section{Coefficient of friction}

The friction coefficient of the sample friction material is related to the time and conditions of the test at $30 \mathrm{~N}$ friction force and a sliding speed of the disc of $0.7 \mathrm{~m} / \mathrm{s}$. The sample density data was used to convert the mass loss into volume loss. The specific wear rate and coefficient of friction of the sample were calculated using equation (3) and equation (4), respectively.

$\kappa$

$=\frac{\Delta V}{\mathrm{~N} \cdot \chi} \#$

Where:

$\kappa=$ Specific wear rate

$V=$ The volume change $\left(\right.$ in $\mathrm{m}^{3}$ )

$\chi=$ Total sliding distance (in $\mathrm{m}$ )

$\mu=\frac{\mathrm{M}}{r \cdot N}$

Where

$\mu=$ Friction coefficient

$\mathrm{M}=$ Torque induced in the specimen due to friction (in N-mm)

$r=$ The disc radius $(\mathrm{mm})$

$\mathrm{N}=$ Normal load acting on the specimen (in N) [42].

\section{Structure and Morphology}

The worn surface of the bio-based hybrid nanocomposite brake pad was sputter-coated with an ultra-thin gold film before microstructure analysis and then examined with SEM. After wear investigation, the BHN brake pad worn microstructure surfaces were analyzed to determine the wear mechanisms under sliding, using a Carl Zeiss Environmental SEM (EVO HD 15 model) operating 1000 times zoom under controlled atmospheric conditions at $20 \mathrm{kV}$ [43-45]. 


\section{RESULTS AND DISCUSSION}

\section{Hardness}

As shown in Table 2, the hardness values of the newly developed and CON brake pads were recorded. The hardness value of the CON was 27.3. In each formulation the variation in hardness values were distinct. This showed that the different formulations of brake pads provided different hardness values. In addition, CON and BHN 4 brake pads had the same hardness values, which shows the same surface rigidity.

Table 2: Hardness Properties of BHN and CON Brake Pads

\begin{tabular}{|c|c|c|c|}
\hline $\begin{array}{c}\text { Biobased Hybrid } \\
\text { Nanocomposite Sample }\end{array}$ & Hardness & Remarks & \\
\hline CON & 27,3 & & \\
\hline BHN 1 & 24,6 & -10 & \\
\hline BHN 2 & 30,7 & 13 & \\
\hline BHN 3 & 26,3 & -4 & \\
\hline BHN 4 & 27,3 & 0 & \\
\hline BHN 5 & 23,5 & -14 & \\
\hline BHN 6 & 31,7 & 16 & \\
\hline
\end{tabular}

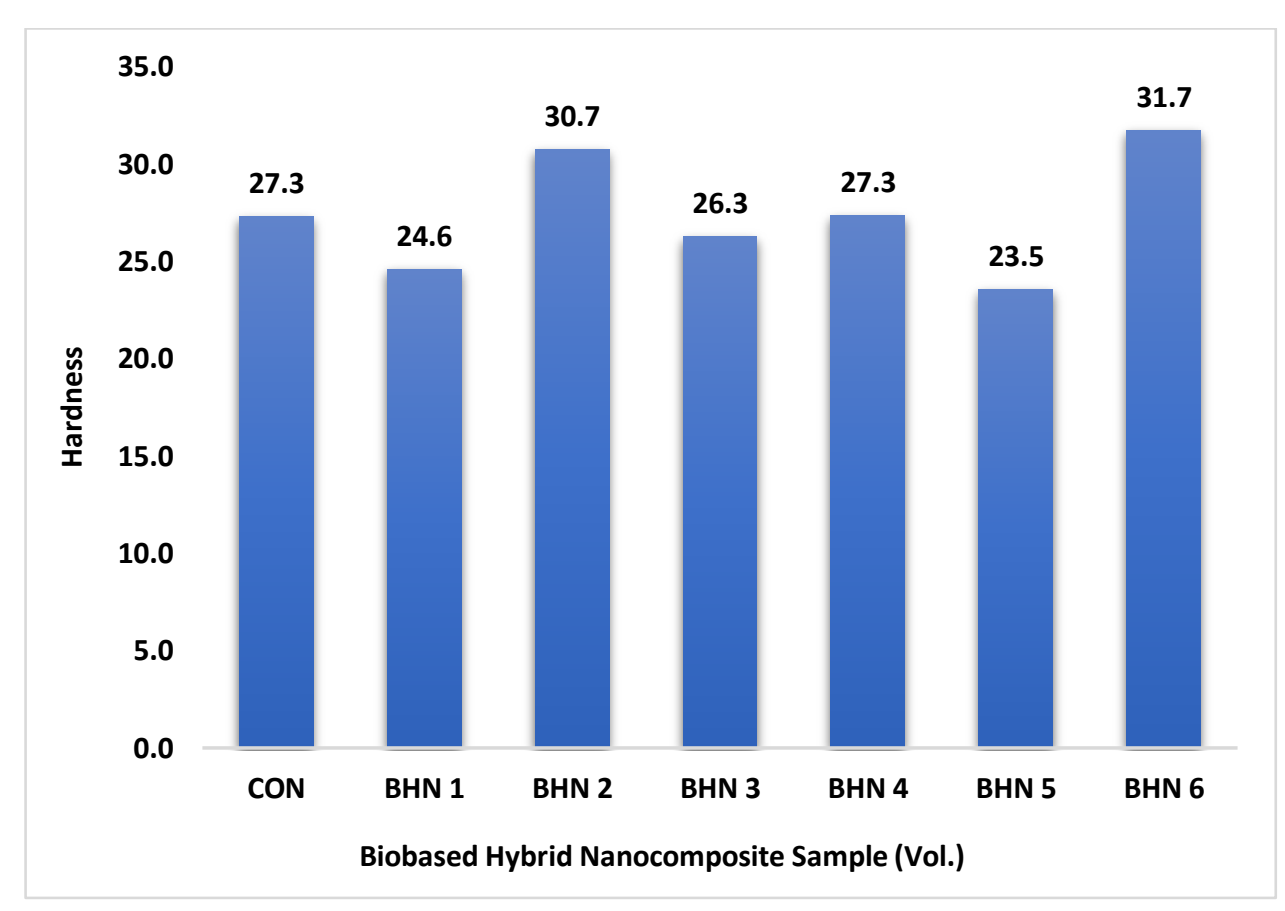

Figure 1: Hardness Properties of BHN and CON Brake Pads.

The high content of friction modifier in the BHN 2 and BHN 6 formulations caused a slight reduction in hardness properties of the developed brake pads. This result is in line with the studies by Gbadeyan [5] and Rukiye et al. [46] in which a higher graphite content reduced the hardness properties of the brake pad. As can be seen in Figure 1, the hardness value of the conventional pad is higher than almost all bio-based nanocomposite brake pad formulations except BHN 2 and BHN 6. The hardness properties of CON brake pads is due to the loading and homogeneous dispersion of the ceramic additive. 
The higher hardness values for BHN 2 and BHN 6 can be attributed to the loading of CNSs in the composition. Therefore, the hardness values of BHN 2 and BHN 6 should be observed because they have better surface toughness than conventional brake pads. Thus, the results show that the hardness properties of the BHN and conventional brake pad were similar.

\section{Compressive Modulus}

As shown in Figure 2 the values of the compression modulus from the linear fraction of the engineering stress and strain bar was compared in graph form with different BHNs and the CON brake pad formulations. The results show that compared to CON, the BHN 2, BHN 3 and BHN 6 brake pads showed higher elastic modulus. This can be attributed to the homogenous distribution of CNSs and graphite nano-powders in the composition. A synergistic interlocking bond with the matrix was formed by this component, which works together to produce a more stable structure that results in better stiffness. Figure 2 shows that the compressive strains of BHN 1, BHN 4, and BHN 5 were lower when compared with the CON pad. When loaded with additives, the brittle behavior of the BHN brake pads group caused the material to break rapidly during testing.

Table 3: Compressive Modulus of BHN and CON Brake Pads.

\begin{tabular}{|c|c|c|}
\hline $\begin{array}{c}\text { Biobased Hybrid } \\
\text { Nanocomposite Sample }\end{array}$ & Compressive Modulus (GPa) & Remarks (\%) \\
\hline CON & 9,30 & \\
\hline BHN 1 & 4,50 & $-51,6$ \\
\hline BHN 2 & 11,11 & 19,4 \\
\hline BHN 3 & 12,32 & 32,5 \\
\hline BHN 4 & 5,11 & $-45,0$ \\
\hline BHN 5 & 6,74 & $-27,5$ \\
\hline BHN 6 & 10,75 & 15,6 \\
\hline
\end{tabular}

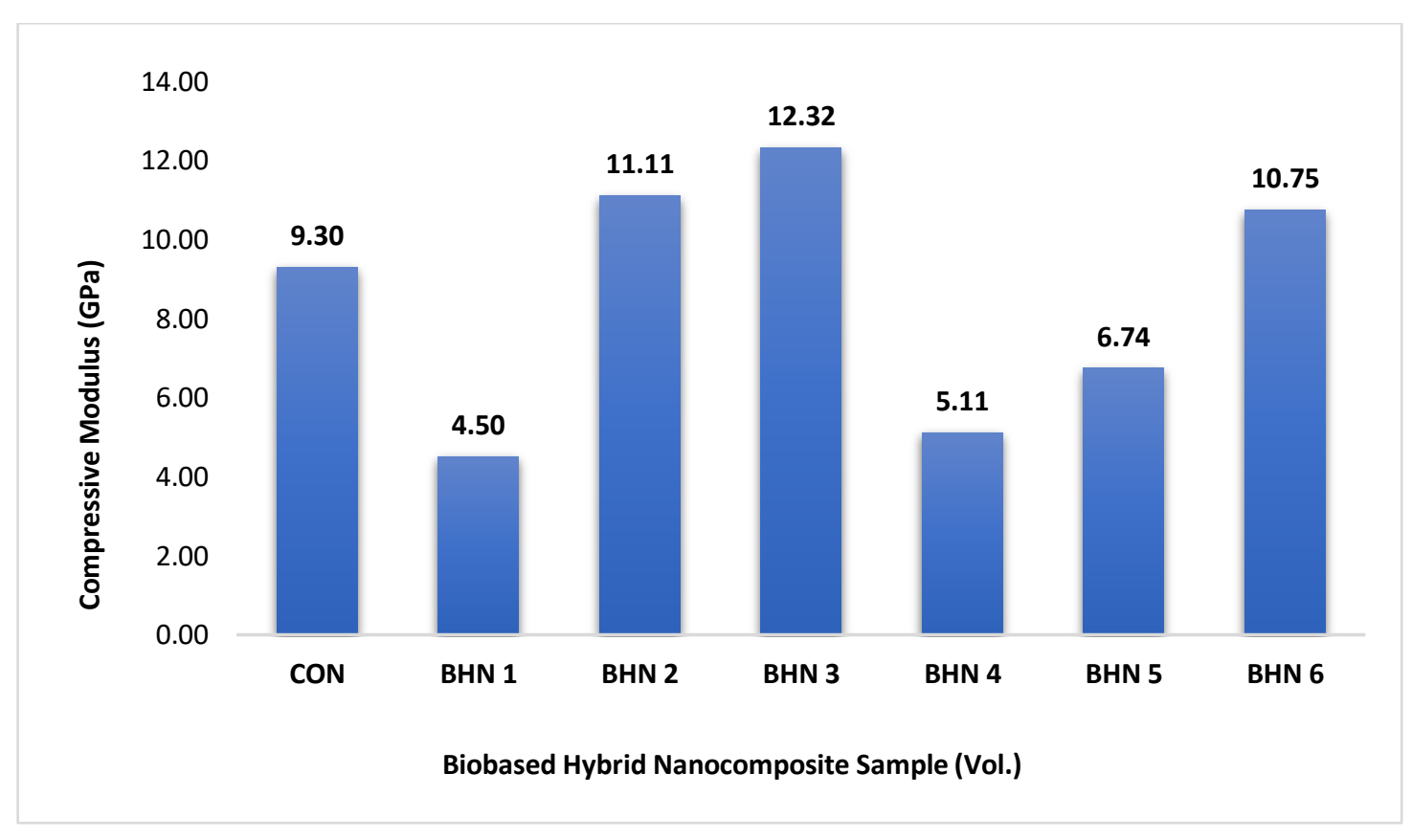

Figure 2: Compressive Modulus of BHN and CON Brake Pads. 


\section{The Absorption Test}

The absorption rate of brake pads generally affects the braking performance [39]. For that reason, the oil and water absorption of the brake pad samples should be investigated. Therefore, the methods used to determine the absorption of brake pads were tested as laid out below.

\section{Water Absorption}

Table 4 shows the conventional and developed brake pad water absorption rate and is illustrated in Figure 3 . The water absorption value of the two brake pads had low variation from $0.185 \%$ to $2.02 \%$ compared with the value $5.03 \%$ recorded by Dagwa and Ibhadode [47] and $5 \%$ to $9 \%$ by Mayowa et al. [48]. The moisture absorption rate of BHN brake pad samples ranged from $0.18 \%$ to $1.97 \%$ which is low compared to the CON brake pads (2.02\%) as shown in Figure 3 . Brake pads BHN 2 and BHN 3 showed water absorption values of $0.18 \%$ and $0.22 \%$, respectively. The water absorption rate of the two samples were relatively low compared to that of the CON brake pads. This major reduction may be due to the interconnecting bond created by the additives.

Table 4: Water Absorption Rate of BHN and CON Brake Pads.

\begin{tabular}{|c|c|c|}
\hline $\begin{array}{c}\text { Biobased Hybrid Nanocomposite } \\
\text { Sample }\end{array}$ & Water absorption (\%) & Remarks \\
\hline CON & 2,02 & \\
\hline BHN 1 & 0,44 & 78 \\
\hline BHN 2 & 0,18 & 91 \\
\hline BHN 3 & 0,22 & 89 \\
\hline BHN 4 & 0,27 & 87 \\
\hline BHN 5 & 0,49 & 76 \\
\hline BHN 6 & 1,97 & 3 \\
\hline
\end{tabular}

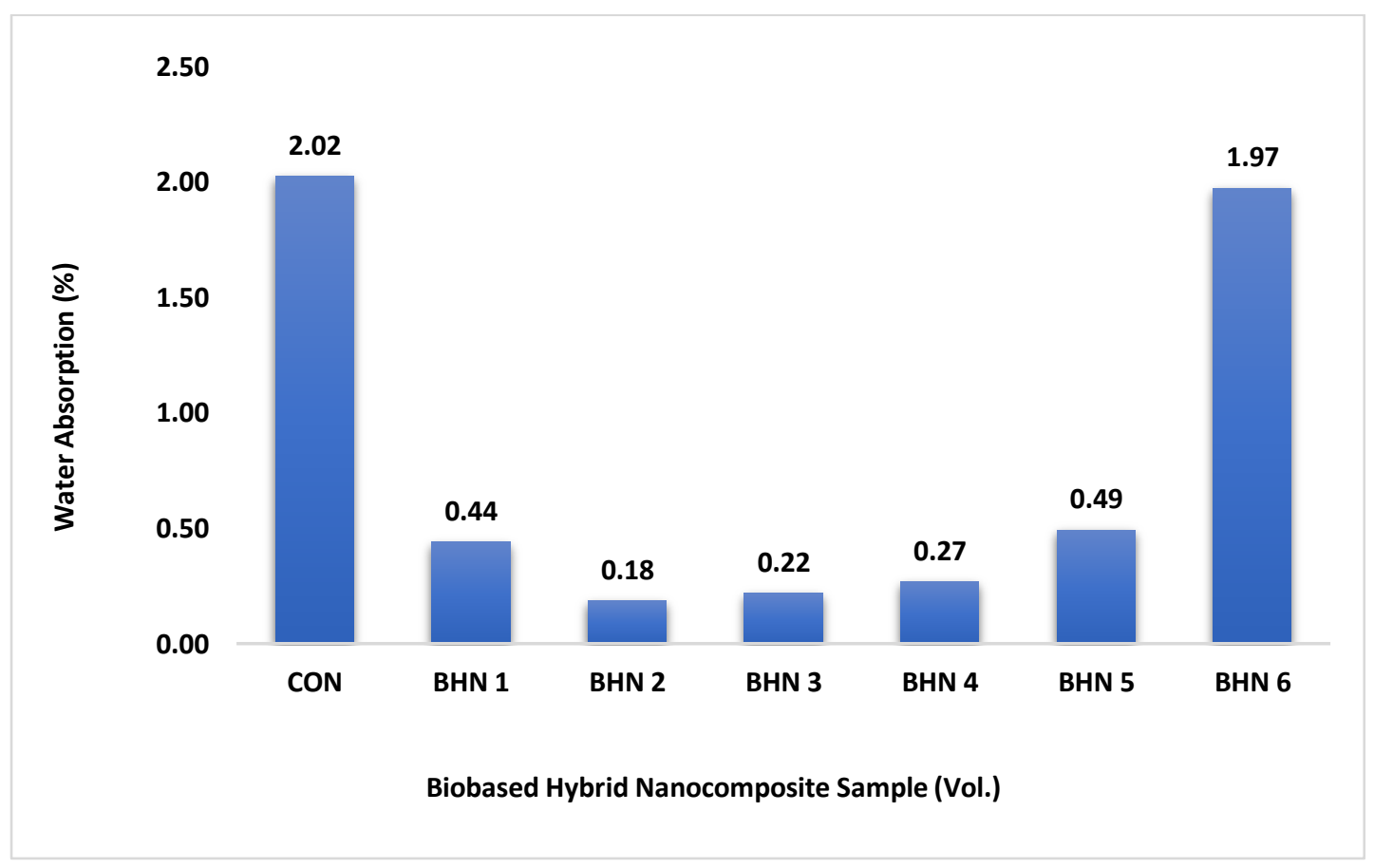


Figure 3: Water Absorption Rate of BHN and CON Brake Pads.

The water absorption of BHN brake pads and CON brake pads compared favorably with the standard conventional brake pad values of $0 \%$ to $4 \%$ [43]. Kim et al. [49] reported that the water absorption increases the weight and thickness of the brake pad, which eventually reduces the brake pad mechanical properties such as compressibility and hardness. These results indicate that the BHN brake pads' low moisture absorption rate prevented performance phenomena variability, for example COF, which agrees with the COF illustrated in Figure 6.

\section{Oil Absorption}

Table 5 shows the values of oil absorption rates of the BHN and CON brake pad samples. The results indicate that the oil absorption rate of BHN pads was lower than CON pads. The absorption of both pads was lower than the $2.34 \%$ recorded by Mayowa et al. [48] and the $0.44 \%$ reported by Dagwa et al. [47]. However, under the same conditions, most of the BHN brake pads absorbed a smaller amount of oil than the CON brake pads. The low absorption rate of the BHN samples could be due to the boundary bond being closer to the carbon-based material.

Table 5: Oil Absorption Rate of BHN and CON Brake Pad.

\begin{tabular}{|c|c|c|}
\hline $\begin{array}{c}\text { Biobased Hybrid } \\
\text { Nanocomposite Sample }\end{array}$ & Oil absorption (\%) & Remarks \\
\hline CON & 0,40 & \\
\hline BHN 1 & 0,32 & 20 \\
\hline BHN 2 & 0,28 & 31 \\
\hline BHN 3 & 0,19 & 52 \\
\hline BHN 4 & 0,16 & 60 \\
\hline BHN 5 & 0,11 & 71 \\
\hline BHN 6 & 0,42 & -5 \\
\hline
\end{tabular}

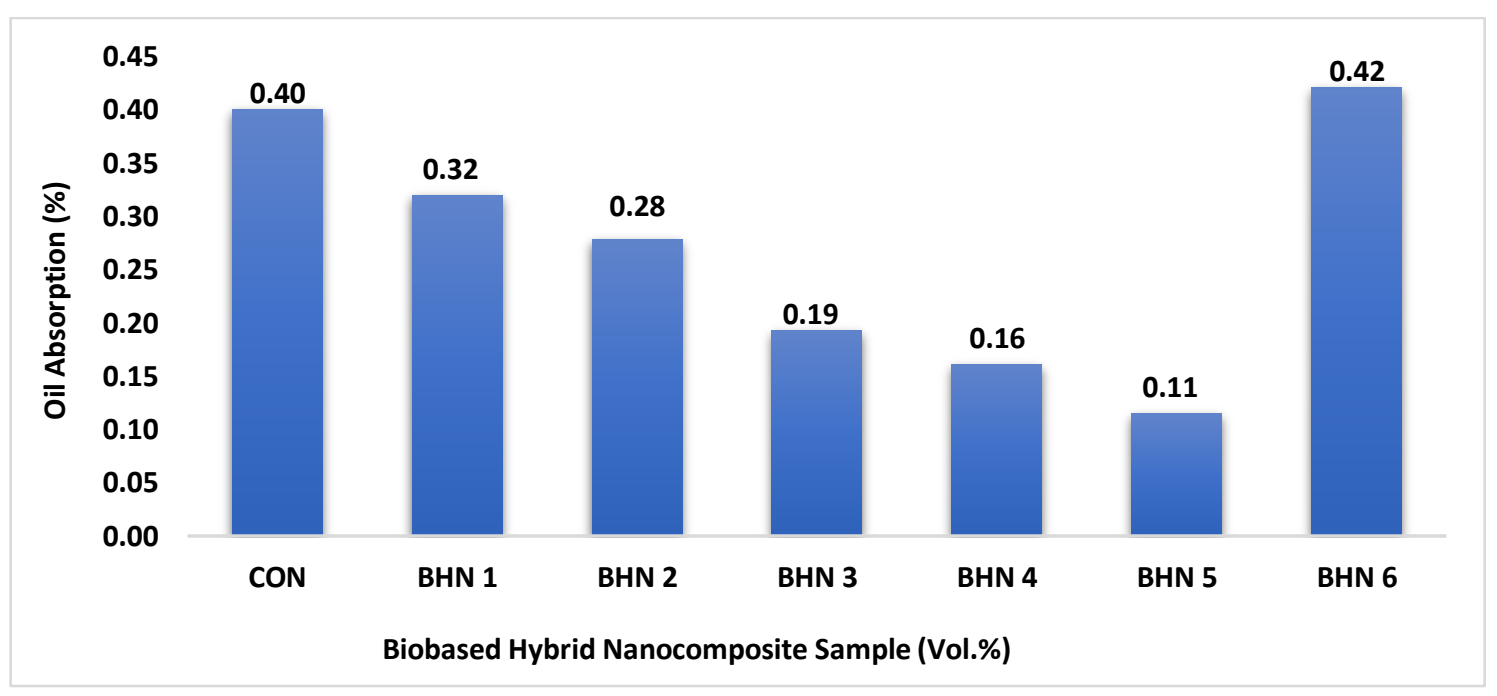

Figure 4: Oil absorption Rate of BHN and CON Brake Pad.

The BHN 6 pads absorbed more oil and had higher absorption capacity than all the rest of the BHN and CON pad samples. The increase in oil absorption could be due to the high loading of graphite nano powder and CNSs. The BHN 5 
oil absorption rate was low $(0.11 \%)$ which was $71 \%$ higher than the $0.40 \%$ absorption rate achieved by CON pad samples.

Figure 4 shows the oil absorption graph of BHN and CON brakes pads for each sample after 24 hours. Increasing the concentration of CNSs reduces the matrix interface between the fibers. This creates holes that make the flow of fluid possible.

\section{Wear Rate}

The wear rate and friction coefficient of BHN brake pad with respect to three different speeds is shown in Table 6 . The variation of BHN and CON brake pads wear rate at three different speeds is shown in Figure 5. As a function of speed, the correlation between the wear rates and formulation of brake pads was measured. The wear rate of all BHN and CON samples was reduced as the speed increased. This could be due to the improved heat resistance and toughness of the additives in the samples. Sample BHN 2 and BHN 6 brake pads showed a low wear rate compared to CON due to high surface hardness. This good wear resistance can be attributed to the uniform distribution of CNSs and binder quality in the matrix. In addition, the shared effect developed by carbon-based additives and the bonding properties of epoxy resin provide excellent component bonding that counteracts abrasion.

Table 6: Coefficient of Friction and Wear Rates of bio-Based Hybrid Brake Pads.

\begin{tabular}{|c|c|c|c|c|c|c|}
\hline $\begin{array}{c}\text { Bio-Based Hybrid } \\
\text { Nanocomposite }\end{array}$ & \multicolumn{2}{|c|}{ Wear Rates (g/Nm) at Different Speeds (m/s) } & \multicolumn{3}{|c|}{$\begin{array}{c}\text { Coefficient of Friction At } \\
\text { Different Speeds (m/s) }\end{array}$} \\
\hline & 433,6 & 1300,8 & 2168,0 & 433,6 & 1300,8 & 2168,0 \\
\hline CON & $3,1 \mathrm{E}-08$ & $1,82 \mathrm{E}-08$ & $1,53 \mathrm{E}-08$ & 0,564 & 0,557 & 0,581 \\
\hline BHN 1 & $8,3 \mathrm{E}-08$ & $3,78 \mathrm{E}-08$ & $2,44 \mathrm{E}-08$ & 0,454 & 0,475 & 0,500 \\
\hline BHN 2 & $2,28 \mathrm{E}-08$ & $1,77 \mathrm{E}-08$ & $1,39 \mathrm{E}-08$ & 0,525 & 0,531 & 0,555 \\
\hline BHN 3 & $2,00 \mathrm{E}-08$ & $1,61 \mathrm{E}-08$ & $1,43 \mathrm{E}-08$ & 0,375 & 0,377 & 0,376 \\
\hline BHN 4 & 3,84E-08 & $1,67 \mathrm{E}-08$ & $1,97 \mathrm{E}-08$ & 0,320 & 0,352 & 0,364 \\
\hline BHN 5 & 3E-08 & $1,07 \mathrm{E}-08$ & $9,53 \mathrm{E}-09$ & 0,525 & 0,531 & 0,555 \\
\hline BHN 6 & 2,84E-08 & 9,31E-09 & $8,25 \mathrm{E}-09$ & 0,388 & 0,394 & 0,423 \\
\hline
\end{tabular}

The correlation of wear rate and speed on BHN 1, BHN 4, and BHN 5 was obvious as the speed increased. As the speed increased the brake pad samples showed a random wear rate. This performance may be due to gradual thermal stress build-up produced as sliding distance increases. Furthermore, it is evident that BHN 2, BHN 3, BHN 6 with 0.3 wt. \% of was lower than other samples, including CON brake pads. This can be attributed to the uniform distribution of the CNSs potential resulting in effective wear resistance. 


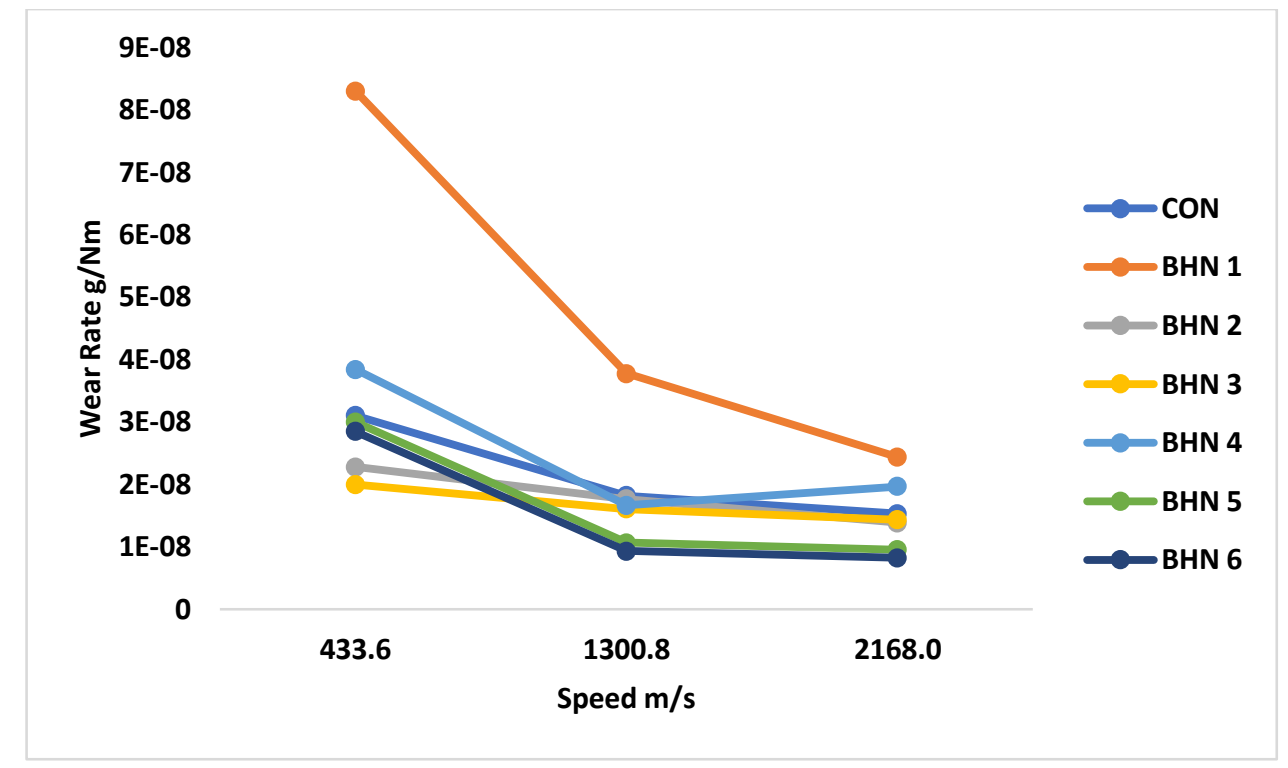

Figure 5: The Variation of Wear Rate With Speed.

This trend of variation of wear rate with speed is consistent with the report by Friedrich et al. [50] where a combination of fiber showed good wear resistance. As reported in the literature, adding CNTs generally improves the thermal and mechanical properties of composite materials. In this respect, the BHN brake pads' lower wear rate could be due to the synergistic functions of graphite nanoparticle (GN) and CNSs which work together to produce a coil resulting in higher strength, better heat absorption, stiffness, and toughness due to more stable structure $[4,50,51]$. The wear test shows that as the CNS content increases, the wear rate reduces. The results also show that by reinforcing the resin and other components, the CNSs improve the wear resistance of friction materials.

According to Ibhadode and Dagwa [52] and Ikpambese et al. [43], increasing the speed increases the contact between the rotor and the brake pads. Therefore, the increase in the wear rate of BHN 1, BHN 4, and BHN 5 are due to the increase in contact between the brake pad and the rotor as the speed increases. This speed increases thermal inductive stress and frictional heat, leading to the breakdown of additives, which finally leads to an increase in wear rates.

\section{Friction Coefficient (COF)}

For good brake pad performance, the friction coefficient value of a pad should range between 0.35 and 0.65 according to the SAE J661 CODE standard value recommended for vehicle brake pad application [53]. The friction coefficient obtained for BHN and CON brake pads was found to be between 0.320 to 0.581 , which is within the standard of the SAE J661 CODE. Table 6 shows the relationship between the speed and the friction coefficient of BHN brake pads. As shown in Figure 6, the COF varies with different formulations of brake pads. As reported by Lee et al. [21] and Lawrence and Paul [39], this fictional performance in the brake pad material formulations can be due to the abrasive filler and friction modifier loading. Figure 6 shows that the BHN brake pads and CON brake pads keep a constant friction coefficient as the speed changes from $433.6 \mathrm{~m} / \mathrm{s}$ to $2168 \mathrm{~m} / \mathrm{s}$. This development is consistent with research by Jang et al. [37] who reported a stable COF in different brake pad formulations. 


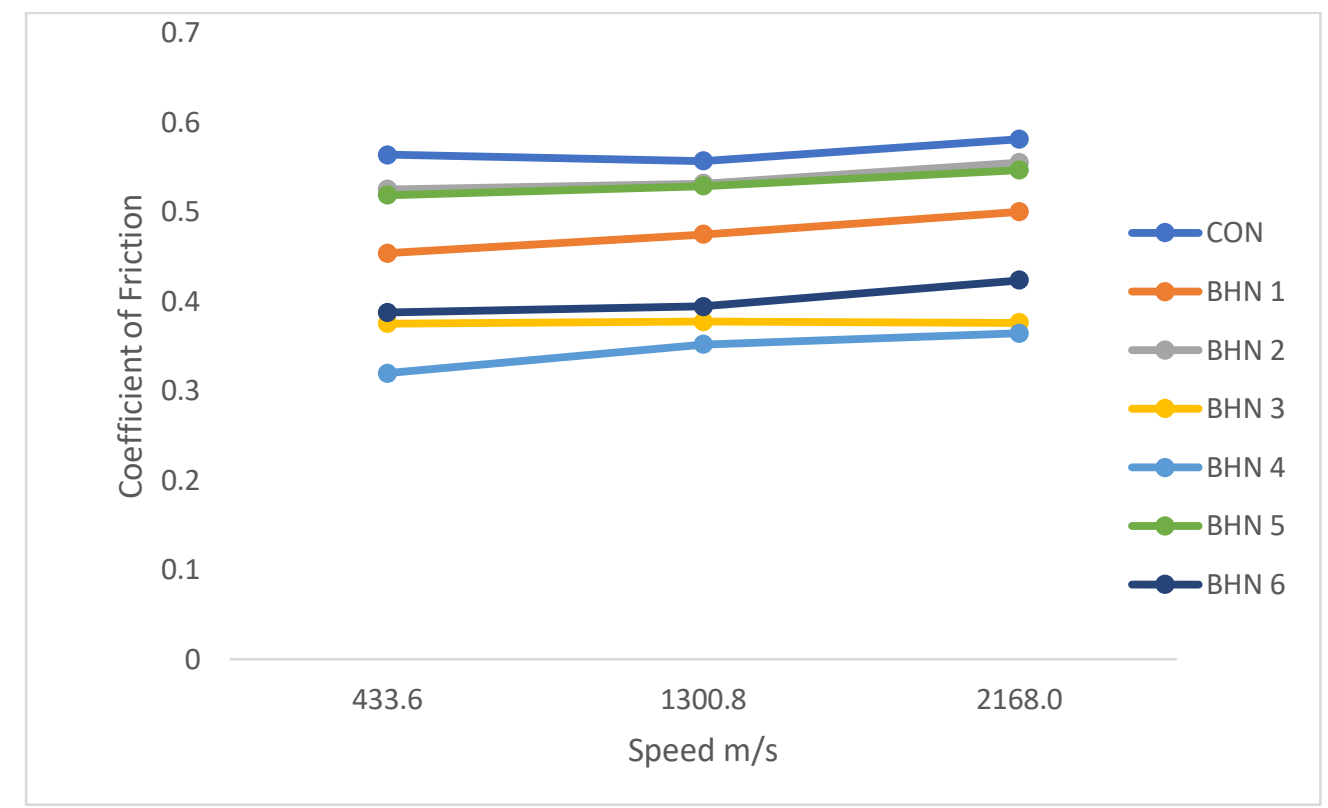

Figure 6: The Coefficient of Friction Variation with Speed.

The BHN brake pads BHN 2 and BHN 5 had a similar friction coefficient value of $0.555 \mu$ which was higher than the COF values of other BHN brake pads. This behavior can be attributed to the amount of CNSs added to the composition. The result is in agreement with Ibhadode and Dagwa [52] who found that high fiber in the composition of brake pads increases COF. Likewise, the stable graphite formation in the composition may be the reason for BHNs' friction coefficient stability. The reduction in BHN 1, BHN 3, BHN 4, and BHN 6 COF may be due to graphite nanoparticles and CNSs interactive lubricating effect and the carbon bonding used as a friction modifier in the formulation of brake pad materials [21, 29].

\section{Scanning Electron Microscopy}

The morphology of the worn surface of CON and BHN brake pads filled with CNSs was investigated to determine the tribological performance of the brake pad samples under a SEM. Figure 7 shows the SEM micrographs of CON and BHN brake pad worn surfaces at 500X magnification. 

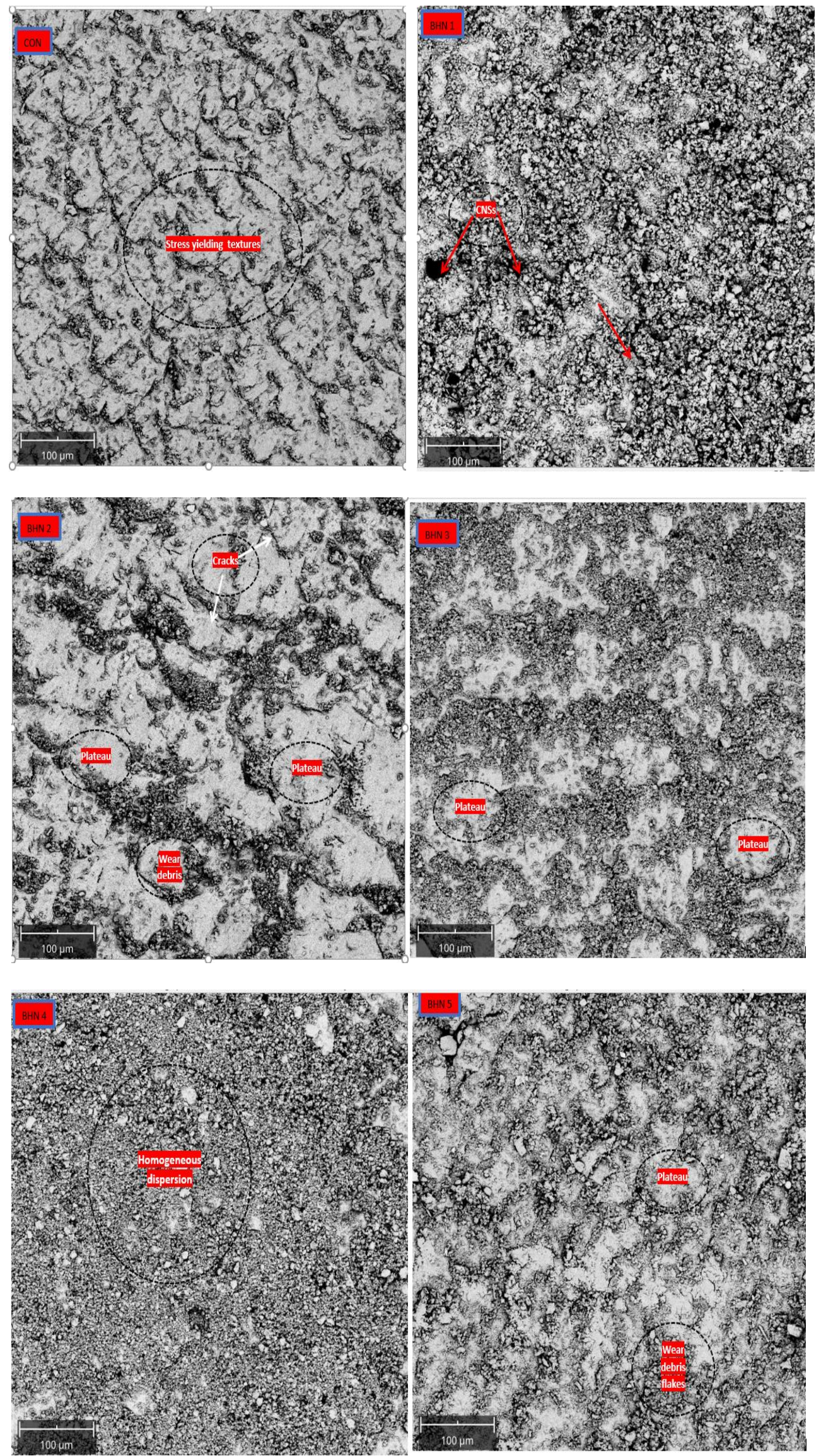


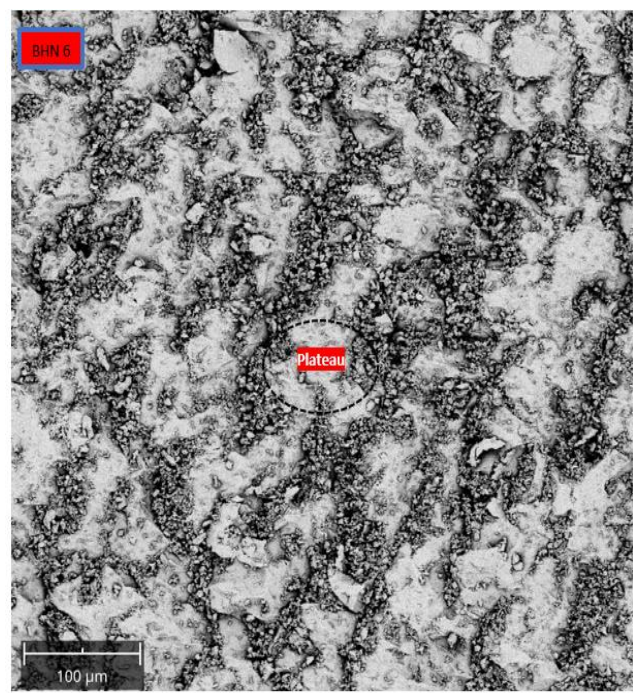

Figure 7: SEM Micrograph of BHN and CON Brake Pads Worn Surfaces.

The order of wear is CON, BHN 1, BHN 2, BHN 3, BHN 4, BHN 5, and BHN 6. In Figure 7 stress yielding textures are observed at the worn surface of the CON brake pad, which could be attributed to the crystallographic textures caused by the deformation of constituents. The stress surface textures may be due to the high amount of tough, abrasive material that controlled abrasion and increased the friction coefficient. Regarding the worn surfaces of the brake pads, homogenous dispersion of CNSs as well as cracks, wear debris, flakes, and plateaus are visible on BHN brake pad worn surfaces. The wear is reportedly structured by the formation of plateaus. The BHN brake pads worn surfaces revealed the structural formation of matrix-enclosed carbon fibers. The cracks were due to the material's toughness and brittleness. BHN1's worn surface clearly shows the presence of CNS bundles, which are tangled and closely embedded in nanocomposite material. Despite all the impact shock, the materials are still intact.

Samples BHN 2 and BHN 5 demonstrated suitable compaction of the wear debris. Therefore, the plateaus were formed at the interface with the metal fiber [54]. The width of plateaus of BHN 2, BHN 3, BHN 5, and BHN 6 nanocomposite samples was about $2 \mu \mathrm{m}$, which is in agreement with the $1 \mu \mathrm{m}$ to $5 \mu \mathrm{m}$ recorded by Eriksson and Jacobson [55]. The primary plateau was formed as the pads wear, which induces increased contact of the surface area between rotor and brake. As the contact area increases wear occurs and the surface becomes smooth. Therefore, the elastic contact component increases, and the actual contact area increases accordingly. The coefficient of friction increases with the defined applying force [54-57]. The smooth surface noticed on the BHN 4 brake pads worn surface may be due to homogenous dispersion of the carbon-based additive. This output may also be attributed to the constant friction coefficient, as shown in Figure 6, and can improve by keeping the brake pad and rotor contact.

\section{CONCLUSIONS}

This study aimed to develop a BHN brake pad application. A mixture of CNSs, graphite nanoparticles, steel nanoparticles, and epoxy resin were used to produce the BHN brake pad samples for solving the braking system problems. CNSs were used to enhance the mechanical and tribological properties of the pad. Graphite nanoparticles were employed as an internal lubricant to control the brake pad wear and friction. Loading of CNSs improved the tribological and mechanical properties of the BHN brake pad. The hardness of the CON brake pad is 27.3, which was slightly higher than the hardness found in 
the BHN brake pads except for BHN2 and BHN6 that were $13 \%$ and $16 \%$ tougher. The uniform dispersion of silicon carbide (ceramic additives) in conventional brake pads results in improved hardness properties.

The water absorption value of $\mathrm{BHN}$ and $\mathrm{CON}$ recorded a lower rate ranging from $0.18 \%$ to $2.02 \%$, which was better than the water absorption value recorded in the literature [47, 48]. However, the moisture absorption rate of BHN brake pads $(0.18 \%$ to $1.97 \%)$ was lower compared to CON brake pads $(2.02 \%)$. The oil absorption rate of BHN and CON differs with several formations. Under the same conditions, most BHN brake pads absorbed less oil than CON brake pads. It was noted that BHN 5 had a $0.11 \%$ lower oil absorption rate, which was $71 \%$ better compared to CON brake pads. This performance was due to lower porosity and the interface bond with carbon-based materials. Therefore, the increase in the BHN pads' oil absorption rate can also be attributed to graphite nanoparticles' loading. According to Ibhadode and Dagwa [52], graphite has a porosity that varies from $0.7 \%$ to $53 \%$. Enticingly, the BHN brake pads with better water/oil absorption properties than the CON pad and other existing pads may show better water/oil resistance when exposed during application.

Furthermore, the BHN brake pad has better tribological properties than the conventional brake pad. The COF of both brake pad samples ranged from 0.3 to 0.5 , which was within SAE J661 CODE standard value (0.3-0.6) as recommended for vehicle brake pad application. The homogenous dispersion and increase in the CNSs increased the COF. The interactive effect of carbon additives and the binder quality led to a low wear rate of the BHN brake pads. The SEM image of the worn surface of CON brake pads reveal inconsistent and stress yielding surface textures, while homogenous dispersion, wear debris, flakes, and plateaus are observed in BHN brake pad surfaces. This structural formation provides better resistance to the effectiveness of the interaction of the asperities between the two rubbing surfaces, which eventually result in improved tribological properties. It may be concluded that the tribological properties of the BHN brake pads depend on CNS and graphite nanoparticle loading.

\section{REFERENCES}

1. H. Hwang, S. Jung, K. Cho, Y. Kim, and H. Jang. Tribological performance of brake friction materials containing carbon nanotubes. Wear. 2010, https://doi.org/10.1016/j.wear.2009.09.003.

2. Y. C. Kim, M. H. Cho, S. J. Kim, and H. Jang. The effect of phenolic resin, potassium titanate, and CNSL on the tribological properties of brake friction materials. Wear. vol. 264, no. 3-4, pp. 204-210, 2008, https://doi.org/10.1016/j.wear.2007.03.004

3. P. Deshmukh, M. Lovell, W. G. Sawyer, and A. Mobley. On the friction and wear performance of boric acid lubricant combinations in extended duration operations. Wear. 2006, https://doi.org/10.1016/j.wear.2005.08.012.

4. O. J. Gbadeyan, K. Kanny, and T. Mohan. Influence of the multi-walled carbon nanotube and short carbon fibre composition on tribological properties of epoxy composites. Tribol. Mater. Surf. Interfaces. 2017, https://doi.org/10.1016/j.wear.2005.08.012

5. O. J. Gbadeyan. Low friction hybrid nanocomposite material for brake pad application. Master's dissertation, Durban University of Technology, Durban, South Africa, 2017.

6. O. J. Gbadeyan and K. Kanny. Tribological behaviors of polymer-based hybrid nanocomposite brake pad. J. Tribol. 2018, https://doi.org/10.1115/1.4038679

7. E. F. EL-kashif, S. A. Esmail, O. A. Elkady, B. Azzam, and A. A. Khattab. Influence of carbon nanotubes on the properties of friction composite materials. J. Compos. Mater. 2020; 54, 2101-2111, 2020. 
8. H. Jang, K. Ko, S. Kim, R. Basch, and J. Fash. The effect of metal fibers on the friction performance of automotive brake friction materials. Wear 2004, https://doi.org/10.1016/S0043-1648(03)00445-9

9. J. Bijwe, M. Kumar, P. Gurunath, and Y. Desplanques. Optimization of brass contents for best combination of triboperformance and thermal conductivity of non-asbestos organic (NAO) friction composites. Wear. 2008, https://doi.org/10.1016/j.wear.2007.12.016.

10. J. Bijwe and M. Kumar. Optimization of steel wool contents in non-asbestos organic (NAO) friction composites for best combination of thermal conductivity and tribo-performance. Wear. 2007, https://doi.org/10.1016/j.wear.2007.01.125.

11. B. Satapathy and J. Bijwe. Performance of friction materials based on variation in nature of organic fibres: Part I. Fade and recovery behaviour. Wear. 2004, https://doi.org/10.1016/j.wear.2004.03.003.

12. K. H. Cho, M. H. Cho, S. J. Kim, and H. Jang. Tribological properties of potassium titanate in the brake friction material; morphological effects. Tribol. Lett. 2008, https://doi.org/10.1007/s11249-008-9362-x.

13. K. N. Kumar and K. Suman. Review of brake friction materials for future development. J. Mech. Mech. Eng. vol. 3, pp. 1-29, 2017.

14. O. Jacobs, W. Xu, B. Schädel, and W. Wu. Wear behaviour of carbon nanotube reinforced epoxy resin composites. Tribol. Lett. 2006, https://doi.org/10.1007/s11249-006-9042-7.

15. A. B. Sulong, J. Park, N. Lee, and J. Goak. Wear behavior of functionalized multi-walled carbon nanotube reinforced epoxy matrix composites. J. Compos. Mater. 2006, https://doi.org/10.1177/0021998306061305.

16. X. H. Men, Z. Z. Zhang, H. J. Song, K. Wang, and W. Jiang. Functionalization of carbon nanotubes to improve the tribological properties of poly (furfuryl alcohol) composite coatings. Compos. Sci. Technol. 2008, https://doi.org/10.1016/j.compscitech.2007.07.008.

17. T. Sing, A. Patnaik, B. Satapathy, and B. Tomar. Development and optimization of hybrid friction materials consisting of nanoclay and carbon nanotubes by using analytical hierarchy process $(A H P)$ and technique for order preference by similarity to ideal solution (TOPSIS) under fuzzy atmosphere. Walailak J. Sci. \& Tech. 2013. https://doi.org/10.2004/wjst.v10i1.357

18. S. Bal and S. Samal. Carbon nanotube reinforced polymer composites-a state of the art. Bull. Mater. Sci. 2007, https://doi.org/10.1007/s12034-007-0061-2.

19. P. J. Harris. Carbon nanotube composites. Int. Mater. Rev. 2004, https://doi.org/10.1179/095066004225010505.

20. O. E Ige, F. L Inambao, and G. A Adewumi. Synthesis of Natural Carbon Nanospheres From Palm Kernel Fiber. Int. J. Mech. Eng. Technol. 2019; 10, 625-641.

21. K.-J. Lee et al.. Tribological and mechanical behavior of carbon nanotube containing brake lining materials prepared through sol-gel catalyst dispersion and CVD process. J. Alloys Compd. 2009, https://doi.org/10.1016/j.jallcom.2008.08.107

22. S. J. Kim, M. H. Cho, K. H. Cho, and H. Jang. Complementary effects of solid lubricants in the automotive brake lining. Tribol. Internat. 2007, https://doi.org/10.1016/j.triboint.2006.01.022.

23. . Han, L. Huang, J. Zhang, and Y. Lu. Optimization of ceramic friction materials. Compos. Sci. Technol. 2006, https://doi.org/10.1016/j.compscitech.2006.02.027.

24. M. H. Cho, J. Ju, S. J. Kim, and H. Jang. Tribological properties of solid lubricants (graphite, Sb2S3, MoS2) for automotive brake friction materials. Wear. vol. 260, no. 7, pp. 855-860, 2006/04/07/ 2006, doi: https://doi.org/10.1016/j.wear.2005.04.003. 
25. H. Jang and S. J. Kim. The effects of antimony trisulfide (Sb2S3) and zirconium silicate (ZrSiO4) in the automotive brake friction material on friction characteristics. Wear. 2000, https://doi.org/10.1016/S0043-1648(00)00314-8.

26. T. Singh, A. Patnaik, B. Gangil, and R. Chauhan. Optimization of tribo-performance of brake friction materials: effect of nano filler. Wear. 2015 https://doi.org/10.1016/j.wear.2014.11.020.

27. O. Gbadeyan, K. Kanny, and M. T. Pandurangan. Tribological, mechanical, and microstructural of multiwalled carbon nanotubes/short carbon fiber epoxy composites. J. Tribol. 2018; 140, 022002.

28. F. Gojny, M. Wichmann, U. Köpke, B. Fiedler, and K. Schulte. Carbon nanotube-reinforced epoxy-composites: enhanced stiffness and fracture toughness at low nanotube content. Compos. Sci. Technol. 2004, https://doi.org/10.1016/j.compscitech.2004.04.002.

29. K. Yang, M. Gu, Y. Guo, X. Pan, and G. Mu. Effects of carbon nanotube functionalization on the mechanical and thermal properties of epoxy composites. Carbon. 2009, https://doi.org/10.1016/j.carbon.2009.02.029.

30. S.-Y. Yang et al.. Synergetic effects of graphene platelets and carbon nanotubes on the mechanical and thermal properties of epoxy composites. Carbon. 2011, https://doi.org/10.1016/j.carbon.2010.10.014.

31. S. Zhou, Q. Zhang, C. Wu, and J. Huang. Effect of carbon fiber reinforcement on the mechanical and tribological properties of polyamide6/polyphenylene sulfide composites. Mater. Des. 2013, https://doi.org/10.1016/j.matdes.2012.08.029.

32. N. Burger, A. Laachachi, M. Ferriol, M. Lutz, V. Toniazzo, and D. Ruch. Review of thermal conductivity in composites: mechanisms, parameters and theory. Prog. Polym. Sci. 2016, https://doi.org/10.1016/j.progpolymsci.2016.05.001.

33. A. Yasmin, J.-J. Luo, and I. M. Daniel. Processing of expanded graphite reinforced polymer nanocomposites. Compos. Sci. Technol. 2006, https://doi.org/10.1016/j.compscitech.2005.10.014.

34. R. Sengupta, M. Bhattacharya, S. Bandyopadhyay, and A. K. Bhowmick. A review on the mechanical and electrical properties of graphite and modified graphite reinforced polymer composites. Prog. Polym. Sci. 2011, https://doi.org/10.1016/j.progpolymsci.2010.11.003

35. J. Li and Y. Xia. The reinforcement effect of carbon fiber on the friction and wear properties of carbon fiber reinforced PA6 composites. Fibers Polym. 2009, https://doi.org/10.1007/s12221-009-0519-5

36. H. Meng, G. Sui, G. Xie, and R. Yang. Friction and wear behavior of carbon nanotubes reinforced polyamide 6 composites under dry sliding and water lubricated condition. Compos. Sci. Technol. 2009, https://doi.org/10.1016/j.compscitech.2008.12.004

37. E. Omrani, P. L. Menezes, and P. K. Rohatgi. State of the art on tribological behavior of polymer matrix composites reinforced with natural fibers in the green materials world. Eng. Sci. Technol. 2016, https://doi.org/10.1016/j.jestch.2015.10.007

38. D. ASTM. Standard test method for indentation hardness of rigid plastics by means of a barcol impressor. In American Society for Testing and Materials, ed, 2001. 2001, vol. vol. D 2583-95.

39. I. Lawrence and U. A. Paul. Critical evaluation/reassessment of (abfm) automotive brake friction materials. Sci. Res. Essays. 2013; 1, 275-288.

40. D. ASTM. Standard Test Method for Water Absorption of Plastics1. In American Society for Testing and Materials, 1998 , vol. D 570-98.

41. R. Edokpia, V. Aigbodion, O. Obiorah, and C. Atuanya. Evaluation of the properties of ecofriendly brake pad using egg shell particles-Gum Arabic. Elsevier, 2014. 
42. K. Friedrich, Z. Zhang, and A. K. Schlarb. Effects of various fillers on the sliding wear of polymer composites. Compos. Sci. Technol. 2005, https://doi.org/10.1016/j.compscitech.2005.05.028.

43. K. Ikpambese, D. Gundu, and L. Tuleun. Evaluation of palm kernel fibers (PKFs) for production of asbestos-free automotive brake pads. J. King Saud University Eng. Sci. 2016, https://doi.org/10.1016/J.JKSUES.2014.02.001.

44. S. Pesetskii, S. Bogdanovich, and N. Myshkin. Tribological behavior of nanocomposites produced by the dispersion of nanofillers in polymer melts. J. Frict. Wear. 2007, https://doi.org/10.3103/S1068366607050091.

45. F.-h. Su, Z.-z. Zhang, and W.-m. Liu. Mechanical and tribological properties of carbon fabric composites filled with several nano-particulates. Wear. 2006, https://doi.org/10.1016/j.wear.2005.04.015

46. R. Ertan and N. Yavuz. The effects of graphite, coke and $\mathrm{ZnS}$ on the tribological and surface characteristics of automotive brake friction materials. Ind. Lubr. Technol Tribol. 2011, https://doi.org/10.1108/00368791111140468.

47. I. M. Dagwa and A. Ibhadode. Some physical and mechanical properties of asbestos-free experimental brake pad. J. Raw Mater. Res. 2015; 3(2).

48. M. Afolabi, O. Abubakre, S. Lawal, and A. Raji. Experimental investigation of palm kernel shell and cow bone reinforced polymer composites for brake pad production. Int. J. Chem.Mater. Res. 2015, https://doi.org/10.18488/journal.64/2015.3.2/64.2.27.40.

49. S. W. Kim, S. J. Lee, B. K. Park, and S. K. Rhee. A comprehensive study of humidity effects on friction, pad wear, disc wear, DTV, brake noise and physical properties of pads. SAE Technical Paper, 0148-7191, 2011.

50. M. H. Cho, S. J. Kim, D. Kim, and H. Jang. Effects of ingredients on tribological characteristics of a brake lining: an experimental case study. Wear. 2005, https://doi.org/10.1016/j.wear.2004.11.021

51. D.-S. Lim, J.-W. An, and H. J. Lee. Effect of carbon nanotube addition on the tribological behavior of carbon/carbon composites. Wear. 2002, https://doi.org/10.1016/S0043-1648(02)00012-1.

52. A. O. A. Ibhadode and I. M. Dagwa. Development of asbestos-free friction lining material from palm kernel shell. J. Braz. Soc. Mech. Sci. Eng. 2008, https://doi.org/10.1590/S1678-58782008000200010.

53. P. J. Blau. Compositions, functions, and testing of friction brake materials and their additives. Oak Ridge National Lab., TN (US), 2001.

54. 54] C. Menapace, M. Leonardi, G. Perricone, M. Bortolotti, G. Straffelini, and S. Gialanella. Pin-on-disc study of brake friction materials with ball-milled nanostructured components. Mater. Des. 2017 , https://doi.org/10.1016/j.matdes.2016.11.065.

55. M. Eriksson and S. Jacobson. Tribological surfaces of organic brake pads. Tribol. Int. 2000, https://doi.org/10.1016/S0301679X(00)00127-4

56. J. Bijwe, N. Aranganathan, S. Sharma, N. Dureja, and R. Kumar. Nano-abrasives in friction materials-influence on tribological properties. Wear. 2012, https://doi.org/10.1016/j.wear.2012.07.023.

57. W. Österle et al. A comprehensive microscopic study of third body formation at the interface between a brake pad and brake disc during the final stage of a pin-on-disc test. Wear. 2009, https://doi.org/10.1016/j.wear.2008.11.023 
